\title{
A Brief Discussion on the Green Synthesis and Characterisation of Copper Nanoparticles (CuNPs)
}

\author{
Naveen Chandra Joshi ${ }^{*^{1}}$, Vivek Kumar ${ }^{2}$, Ajay Singh ${ }^{3}$ \\ ${ }^{1}$ Assistant Professor, Department of Chemistry, Uttaranchal University Dehradun (India) \\ ${ }^{2}$ Project Fellow, Department of Chemistry, Uttaranchal University Dehradun (India) \\ ${ }^{3}$ Professor, Department of Chemistry, Uttaranchal University Dehradun (India) \\ *Email: drnaveen06joshi@gmail.com
}

\begin{abstract}
The scope of nanotechnology in the field of chemistry offers many applications and one of major applications is the synthesis of metal and metal oxide nanoparticles in the green manner. Copper $(\mathrm{Cu})$ is nontoxic and have many medicinal and other importance. It is a cheaper and good antibacterial and antifungal agent and widely used in the catalytic and sensors. Various methods have been reported in literature for the synthesis of copper nanoparticles (CuNPs). The biological/green methods taking part the copper salt and plant extracts are more efficient, very low cost and better alternatives over such methods. The chacterisation methods used for analysis of CuNPS are very important in the evaluation of their functional aspects. The common characterization techniques are Fourier transform infra-red (FTIR) spectroscopy, UV-Visible spectroscopy (UVVis), Scanning electron microscopy (SEM), Transmission electron microscopy (TEM), X-ray diffractometry (XRD), Dynamic light scattering (DLS) etc.
\end{abstract}

Keywords: Nanoparticles; Copper; Green synthesis; Antimicrobial properties; Characterizations.

\section{INTRODUCTION}

Recently, nanotechnology has used in the different fields like pathogenic diseases, drugs, cancers, synthesis of magnetic nanoparticles, carbon nano tubes, nanofilms, nanoscale transistors, nanowires, catalysis, biological labeling, sensors etc [1]. The applications of nanotechnology in the fields of nanoparticles and nanomaterials are emerging very rapidly $[2,3]$. In general, nanotechnology deals with the size 1-100 nanometers for any atom, molecule or materials and makes the material faster, smaller, and durable and stronger [4]. Nanotechnology is concerned with an opportunity to enhance the new technology and processes in industries as environmentally friendly but it need the development and commercialization. The green nanoparticles synthesised from green or biological methods have an excellent chemical composition and sizes. Such particles are considerably used in the fields like medical biology, microbiology, electronics and cleaning technologies [5-8]. Copper is a nontoxic metal and has identified as a safe inorganic material. Copper nanoparticles (CuNPs) are used in the different fields, including agricultural, engineering and industrial fields [9]. CuNPs show remarkable catalytic, electrical, optical and antimicrobial properties. Presently, the researches have been focused on the useful properties of CuNPs in nanomedicines due their antimicrobial activities [1014]. The biosynthetic approach for the manufacture of copper nanoparticles is an efficient, very low cost, simple and eco-friendly as compared to other conventional methods [15].

\section{GREEN SYNTHESIS CHARACTERISATIONS OF CuNPs}

AND

Currently, the green processes have been applied for the synthesis of metal nanoparticles better alternatives over the conventional physical and chemical methods [16]. Green synthesis of nanoparticles is highly efficient, environmentally friendly and low cost and requires very less instruments/chemicals $[17,18]$. In these methods the plant extracts, microorganisms and natural polymers have been applied [19-22]. The collected parts of the plant are washed carefully using distilled water. Now these parts are cutted into small pieces and make them homogeneous. Such leaves are mixed with required amount of distilled water and then boiled at a specific temperature. Finally, the volume of the contents reduced about ten times by boiling and this is used as plant extract. A certain amount of plant extract mixed with copper sulphate solution for ten to twelve hours (Fig.1). The reduced size of copper is now subjected to the characterizations [23-29]. The characterization techniques used to analyse the copper nanoparticles are UV-visible, FT-IR, FESEM, TEM, XRD, DLS, AFM [28-29] etc (Table 1). 


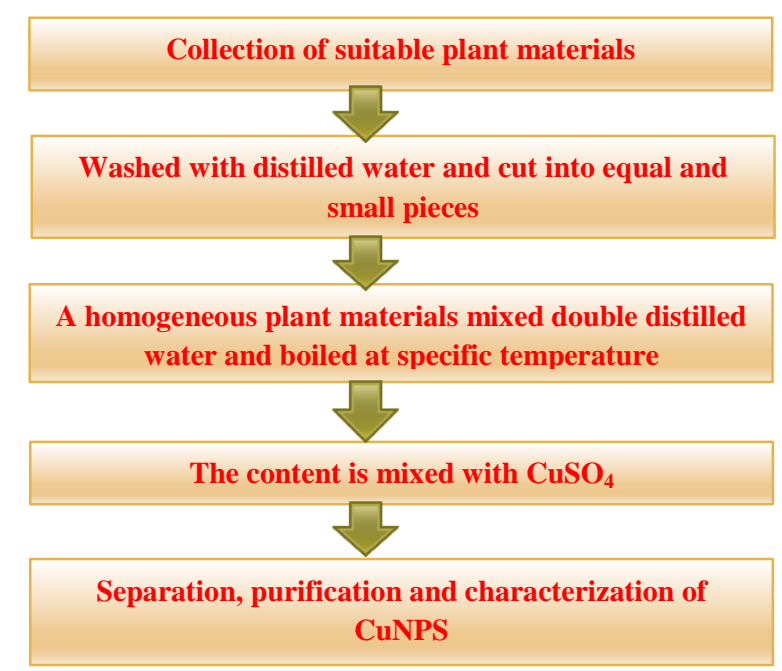

Fig. 1 Green Synthesis of Copper Nanoparticles (CuNPS)

Table 1 Characterization methods for CuNPS

\begin{tabular}{|c|l|}
\hline $\begin{array}{c}\boldsymbol{U V} \text { - } \\
\text { Visible }\end{array}$ & $\begin{array}{l}\text { Ultraviolet-Visible spectroscopy is based on the dissolution of nanoparticles in a suitable solution and } \\
\text { the absorption of wavelength surface plasmon resonances. }\end{array}$ \\
\hline $\boldsymbol{F T}$-IR & $\begin{array}{l}\text { Fourier transform infra-red spectroscopy is used to the presence of various functional groups and bonds } \\
\text { on the synthesized CuNPs and it also explains the surface chemistry of nanomaterials. }\end{array}$ \\
\hline $\boldsymbol{X P S}$ & $\begin{array}{l}\text { The X-ray photo electron spectroscopy is based on escaping of electrons from nano surface under } \\
\text { vacuum conditions and formation of spectra. It is basically used for qualitative, quantitative as well as } \\
\text { semi quantitative analysis. }\end{array}$ \\
\hline $\boldsymbol{X R D}$ & $\begin{array}{l}\text { X-ray diffraction techniques are used to observe the interatomic distances between nanoparticles by } \\
\text { using Bragg's equation. It is based on the reflected X-rays which pass through the powdered } \\
\text { nanomaterials. }\end{array}$ \\
\hline $\boldsymbol{D L S}$ & $\begin{array}{l}\text { Dynamic light scattering technique depends on interaction of light with nanoparticles and used to } \\
\text { determine the particle size between 2-500 nanometers. }\end{array}$ \\
\hline $\boldsymbol{F E S E M}$ & $\begin{array}{l}\text { Field Emission Scanning Electron Microscope (FESEM) method is related to morphological behavior } \\
\text { of nanoparticles and the surface characteristics of nanosurfaces. }\end{array}$ \\
\hline $\boldsymbol{T E M}$ & $\begin{array}{l}\text { Transmission electron microscopy is used in the characterizations of all nanoparticles and provides } \\
\text { compositions, morphology, particles size and crystal behaviors. }\end{array}$ \\
\hline $\boldsymbol{A F M}$ & $\begin{array}{l}\text { Atomic force microscopy explains the dispersion and aggregation of nanoparticles with their size, } \\
\text { shape and structures. }\end{array}$ \\
\hline
\end{tabular}

\section{RECENT STUDIES}

Recently, copper $(\mathrm{Cu})$ nanoparticles have been synthesised, characterised and applied in various fields by different researchers. Patil and coworkers [30] have considered important role of CuNPS in the advancement of nano sciences. They have synthesised CuNPS by using a novel reducing agent and characterised by using XRD, SEM and XPS. The synthesised CuNPS were mixed with commercial CuNPS to observe the optimum sintering energy. Bogoslovskaja [31] et al. reported the antimicrobial effect of CuNPS with varyning their size and phase compositions. The CuNPS were found very effective to inhibit gram positive and gram negative bacteria (Staphylococcus albus and Escherihia coli).
Gondwal and Pant [32] have synthesized CuNPS by using the leaves extract of of Cassia occidentalis. The formations of CuNPS have been confirmed by UVVis spectra. The morphological and other characteristics features of CuNPS were determined by using transmission electron microscopy (TEM), scanning electron microscopy (SEM) with X-ray energy dispersive spectrophotometer (EDX) and Xray diffraction (XRD). The freshy synthesized CuNPS showed effective antimicrobial activity for Escherichia coli and Salmonella typhi. Mahmoodi [33] et al. considered the potential antimicrobial nature of copper nanoparticles and revealed that the CuNPS possess potent antimicrobial activities to treat infectious deseases. 


\section{International Journal of Research in Advent Technology, Vol.7, No.4, April 2019 E-ISSN: 2321-9637 \\ Available online at www.ijrat.org}

Mandava [34] has demonstrated the increased antimicrobial activity of some conventional antibiotics i.e. ampicillin, amoxicillin, gentamicin and ciprofloxacilin, when mixed with copper nanoparticles. He has evaluated the effectiveness of ampicillin with CuNPS and incorporated the mechanisms for this activity of CuNPS. Gopinath [35] et al. has considered an efficient greener method for synthesis of copper nanoparticles using leaf extract of leaf extract of Nerium oleander copper sulphate. The nanoparticles have been well characterized by using UV-Vis Spectrophotometer and FT-IR. The potential antimicrobial activity of CuNPS has been observed for Escherichia coli, Staphylococcus aureus, Klebsiella pneumoniae, Salmonella typhi and Bacillus subtilis. Jayandran [36] reported the green synthesis of copper nanoparticles by using the lemon extract. The method was found cost effective and environment friendly. The copper nanoparticles have been characterized by using the analytical techniques like UV-Vis, IR, XRD, SEM and TEM. He had found a higher antimicrobial activity of copper nanoparticles synthesized from lemon extract to destroy different bacterial strains

\section{CONCLUSIONS:}

The conventional methods are generally used to synthesize metal nanoparticles are suffering with high cost, poor efficiency and needed harmful chemicals. This review represents the greener method used for CuNPs by using some locally available biomasses as reducing agents. It covers characterization techniques, antimicrobial activities of CuNPs with some current studies.

\section{REFERENCES:}

[1] V.D. Krishna, K.W. Diqing, S. Maxim, C.J. Cheeran,J.P. Wang, A. Perez. "Nanotechnology: Review of concepts and potential application of sensing platforms in food safety". Food Microbiology, 75: 47-54, 2018.

[2] H. Bar, D.K. Bhumi, P. Gobinda sahoo, P. Sarkar, P.D. Sankar. "Green synthesis of silvernanoparticles using latex of Jatropha curcas". Colliod surface A, 39:134-139, 2009.

[3] S. Kaviya, J. Santhanalakshmi, B. Viswanathan. "Green Synthesis of silver anoparticles using Polyalthia longifolia Leaf extract along with DSorbitol" Journal of nanotechnology, 1-5, 2011.

[4] Handbook on Nanoscience, Engineeering and Technology, 2nd Ed., Taylor and Francis, 2007.

[5] V. Mironov et al. "Nanotechnology in vascular tissue engineering: from nanoscaffolding towards rapid vessel biofabrication". Trends Biotechnol., 26:338-344,2008.

[6] J. Shi et al. "Nanotechnology in drug delivery and tissue engineering: From discovery to applications". Nano Lett, 10:3223-3230, 2010.
[7] O.S. Koushik et al. "Nano Drug Delivery Systems to Overcome Cancer Drug Resistance A Review". J Nanomed Nanotechnol, 7: 378, 2016.

[8] H.J. Ko. "Recent Update of Nanobiosensors Using Olfactory Sensing Elements and Nanomaterials". Biosens J, 4:129, 2015.

[9] G. Shobha, M. Vinutha, S. Ananda. "Biological synthesis of copper nanoparticles and its impact - a review”. Int J Pharmaceut Sci Invent. 3:28$38,2014$.

[10] W.K. Han, J.W. Choi, G.H. Hwang, S.J. Hong, J.S. Lee, S.G. Kang. "Fabrication of $\mathrm{Cu}$ nano particles by direct electrochemical reduction from $\mathrm{CuO}$ nano particles". App Surf Sci, 252:2832-2838, 2006.

[11] A.A. Ponce, K.J. Klabunde. "Chemical and catalytic activity of copper nanoparticles prepared via metal vapor synthesis". J Mol Catal, 225:1-6, 2005.

[12] Z. Huang, F. Cui, H. Kang, J. Chen, X. Zhang, C. Xia. "Highly dispersed silica-supported copper nanoparticles prepared by precipitationgel method: A simple but efficient and stable catalyst for glycerol hydrogenolysis". Chem Mater, 20:5090-5099, 2008.

[13] N.A. Dhas, C.P. Raj, A. Gedanken. "Synthesis, characterization, and properties of metallic copper nanoparticles".Chem Mater, 10:14461452, 1998.

[14] B.K. Park, S. Jeong, D. Kim, J. Moon, S. Lim, J.S. Kim. "Synthesis and size control of monodisperse copper nanoparticles by polyol method". J Colloid Interface Sci, 311:417-424, 2007.

[15] R. Muhammad et al. "A Review on Synthesis, Characterization and Applications of Copper Nanoparticles Using Green Method". Nano, 12: 04, 2017.

[16] B.M. Ravindra, L.N. Seema, T.M. Neelambika, S.M. Gangadhar, K. Nataraja, K. S. Vijaya. "Silver nanoparticles synthesized by in-vitro derived plants and Callus culture of Clitoriaternatea; evaluation of antimicrobial activity". Research in Biotechnology, 3: 26-38, 2012.

[17] H. A. Salam, P. Rajiv, M. Kamaraj, P. Jagadeeswaran, S. Gunalan and R. Sivaraj. "Plant: Green route for nanoparticles synthesis. International". Research Journal of Biological Sciences, 1: 85-90, 2012.

[18] A. E. Lamb, C. W. N. Anderson, R. G. Haverkamp. "The extraction of gold from plants and its application to phytomining". Chemistry of New Zealand, 65: 31-33,2001.

[19] H. Soheyla, B. Hamed, G.F. Eshrat, N. Farzaneh. "Green synthesis of copper oxide nanoparticles using Penicillium 
aurantiogriseum, Penicillium citricum and Penicillium waksmami”. Digest Journal of nanomaterial and biostructure, 7: 9991005,2010

[20] R. Abdul, I. Amri, J. Desi, M. Stella, and S. Hanggara. "Synthesis of copper oxide nanoparticles by using Phormidiumcyanobacterium" International Journal of Chemistry, 9: 355-360,2009.

[21] S. L. Amrut, J. S. Satish, B. P. Ramchandara, S. N. Raghumani. "Synthesis and optical characterization of copper oxide nanoparticles". Advance in applied Science Research, 1: 36-40, 2010.

[22] M. Shloma, M. Grouchko and A. Kamyshny. "Copper nanoparticles for printed electronics: Routes towords achieving oxidation stability". Journal of Materials, 3: 4626-4638, 2010.

[23] L.S.B. Upadhyay, N. Kumar. "Green synthesis of copper nanoparticle using glucose and polyvinylpyrrolidone (PVP)". Inorganic and Nano-Metal Chemistry, 47: 1436-1440,2017.

[24] S. Thakur, S. Sharma, S. Thakur, R. Rai. "Green Synthesis of Copper Nano-Particles Using Asparagus adscendens Roxb. Root and Leaf Extract and Their Antimicrobial Activities". International Journal of Current Microbiology and Applied Sciences, 7:4, 2018.

[25] I. Subhankari, P. Nayak. "Synthesis of Copper Nanoparticles Using Syzygium aromaticum (Cloves) Aqueous Extract by Using Green Chemistry". World, 2 : 14-17,2013.

[26] X. Song, S. Sun, W. Zhang, Z. Yin, “A method for the synthesis of spherical copper nanoparticles in the organic phase". Journal of colloid and interface science, 273: $463-$ 469,2004.

[27] N.V. Surmawar, S.R. Thakare, N.T. Khaty. "One-Pot, Single Step Green Synthesis of Copper Nanoparticles: SPR Nanoparticles". International Journal of Green Nanotechnology, 3: 302-308,2011.

[28] G. Yang, S. Chai, X. Xiong, S. Zhang, L. Yu, P. Zhang. "Preparation and tribological properties of surface modified $\mathrm{Cu}$ nanoparticles". Trans Nonferrous Met Soc China, 22: 366-372, 2012.

[29] D. Vasudev, Kulkarni, S. Pramod, Kulkarni. "Green Synthesis of Copper Nanoparticles Using Ocimum Sanctum Leaf Extract". 1: 2, 2013.

[30] Patil, S.A., Ryu, CH. \& Kim, HS. Synthesis and Characterization of Copper Nanoparticles (Cu-Nps) using Rongalite as Reducing Agent and Photonic Sintering of $\mathrm{Cu}-\mathrm{Nps}$ Ink for Printed Electronics Int. J. of Precis. Eng. and Manuf.-Green Tech. (2018) 5: 239. https://doi.org/10.1007/s40684-018-0024-7
[31] Bogoslovskaja, O.A., Rakhmetova, A.A., Ovsyannikova, M.N. et al. Antimicrobial effect of copper nanoparticles with differing dispersion and phase composition Nanotechnol Russia (2014) 9: 82. https://doi.org/10.1134/S1995078014010042

[32] Manjul Gondwal and Geeta Joshi nee Pant Synthesis and Catalytic and Biological Activities of Silver and Copper Nanoparticles Using Cassia occidentalis Int J Biomater. 2018; 2018: 6735426

[33] Shirin Mahmoodi, Asghar Elmi and Somayeh Hallaj-Nezhadi Copper Nanoparticles as Antibacterial Agents J Mol Pharm Org Process Res 2018, Vol 6(1): 140

[34] K. Mandava, K. Kadimcharla, N.R. Keesara, S.N. Fatima, P. Bommena and U.R. Batchu. Green Synthesis of Stable Copper Nanoparticles and Synergistic Activity with Antibiotics, Indian J Pharm Sci 2017;79(5):695-700

[35] M.Gopinath and R.Subbaiya M.Masilamani Selvam and D.Suresh, Synthesis of Copper Nanoparticles from Nerium oleander Leaf aqueous extract and its Antibacterial ActivityInt.J.Curr.Microbiol.App.Sci (2014) 3(9) $814-818$

[36] M. Jayandran1M. Muhamed Haneefa2and V. BalasubramanianGreen synthesis of copper nanoparticles using natural reducer and stabilizer and an evaluation of antimicrobial activity J. Chem. Pharm. Res., 2015, 7(2):251259 